\title{
Pólipo e cálculo assintomático de vesícula biliar
}

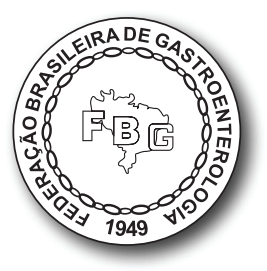

Júlio C. U. Coelho

João Rafael Bora Ruggeri

Juan Carlos Dueñas da Silva

\section{PÓLIPO DA VESÍCULA BILIAR}

Pólipo da vesícula biliar é uma condição comum e quase sempre benigna e assintomática. Sua incidência é extremamente variável na literatura, 1 a $12 \%$. Os pólipos ocorrem em qualquer idade, mas são mais comuns entre 30 e 60 anos de idade. São um pouco mais comuns nos homens, em uma proporção de 1,2 a 1,5 homens por uma mulher.

Os pólipos da vesícula biliar são mais comuns em pacientes com colangite esclerosante primária e em pacientes com síndromes polipoides intestinais congênitas, como síndrome de Peutz-Jeghers e síndrome de Gardner.

\section{Classificação}

Eles podem ser classificados em não neoplásicos e neoplásicos. O pólipo mais frequente é o pólipo de colesterol (60 a 70\%). Os adenomas correspondem a somente 4 a $10 \%$ dos pólipos da vesícula biliar. Apesar de incomuns, é importante que esses pólipos sejam reconhecidos e tratados pelo potencial de evoluírem para carcinoma, principalmente os adenomas $>1 \mathrm{~cm}$.

\section{Manifestações clínicas}

A quase totalidade dos pólipos de vesícula biliar é assintomática (Quadro 1). Entretanto, em raros casos, o pólipo pode se desprender da mucosa e obstruir o ducto cístico causando cólica biliar ou, mais raramente, colecistite aguda. A passagem do pólipo através do ducto cístico e posteriormente pela papila maior (papila de Vater) pode causar pancreatite aguda. 
Quadro 1 Manifestações clínicas dos pólipos de vesícula biliar

\begin{tabular}{l}
\hline - Assintomático (quase totalidade) \\
\hline - Sintomático: \\
\hline - Cólica biliar (destacamento e/ou obstrução) \\
\hline - Colecistite aguda acalculosa \\
\hline - Pancreatite aguda
\end{tabular}

\section{Diagnóstico}

A diferenciação entre pólipo e cálculo pequeno pode ser difícil. Na ultrassonografia (USG), os pólipos não produzem sombra acústica e são fixos à parede da vesícula biliar. A realização adicional de Doppler durante a USG abdominal pode aumentar a precisão na identificação de pólipos pré-malignos ou malignos. Estes pólipos são vascularizados.

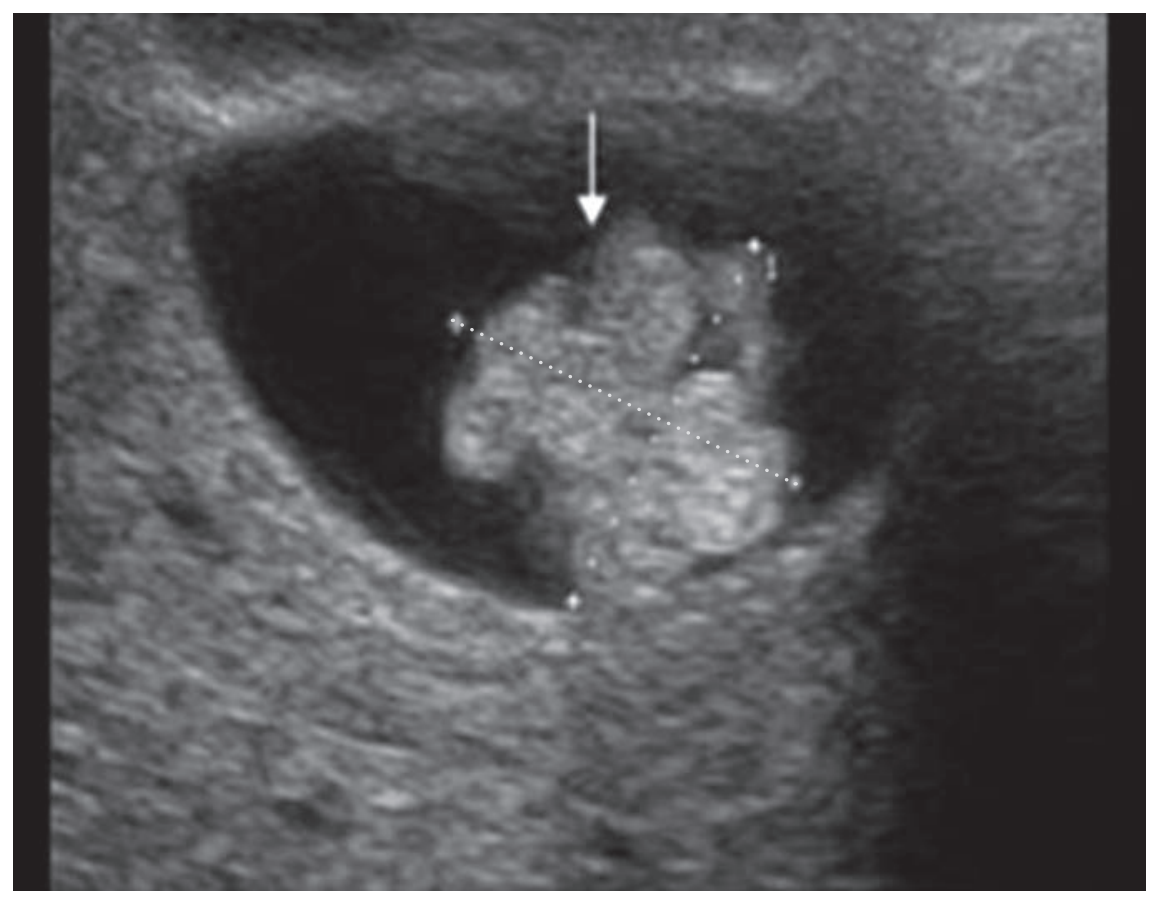

Figura 1 Ultrassonografia abdominal mostrando um pólipo de vesícula biliar de $2 \mathrm{~cm}$ e de superfície irregular (seta). $\bigcirc$ exame anatomopatológico confirmou o diagnóstico de adenocarcinoma de vesícula biliar. 
Apesar de novos exames de imagem como USG tridimensional, USG de alta resolução, imagem harmônica e ecoendoscopia serem mais precisos do que a USG abdominal na diferenciação entre pólipos malignos e benignos, o papel desses exames na indicação de colecistectomia em pacientes com pólipos da vesícula biliar permanece controverso.

\section{Tratamento}

Apesar de não haver consenso, a maioria dos autores indica colecistectomia em pacientes com pólipo de vesícula biliar nas condições evidenciadas no Quadro 2.

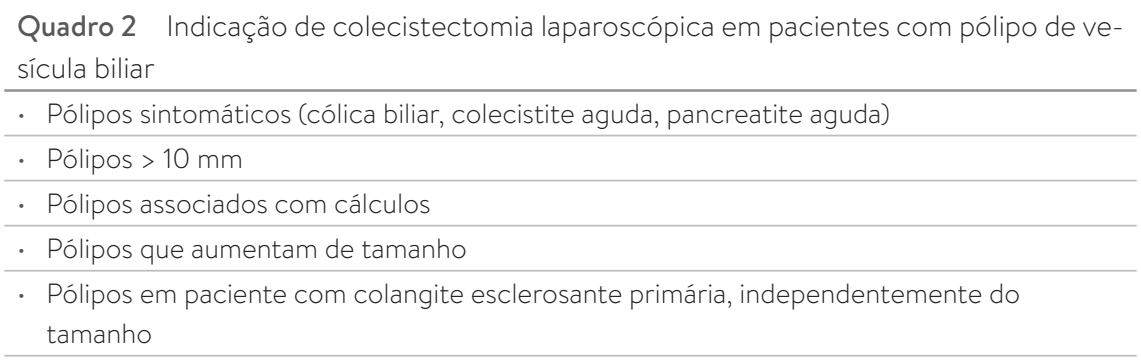

Para pólipos que não apresentam as características mencionadas no Quadro 2, está indicada a realização de USG periódica a cada 6 a 12 meses por 5 a 10 anos. Se não houver crescimento do pólipo, o pólipo é considerado não neoplásico e não existe indicação de continuar o acompanhamento.

Atualmente, a colecistectomia laparoscópica é o método preferencial para o tratamento de pólipos da vesícula biliar. Após a exérese da vesícula biliar, ela deve ser avaliada pelo cirurgião. Em caso de suspeita de malignidade, o pólipo deve ser avaliado por exame de anatomia patológica de congelação perioperatório. Se houver comprovação de malignidade e o carcinoma for de estágio superior a T1a (tumor que invade a lâmina própria), a operação deve ser convertida para a via aberta e o procedimento deve ser ampliado. Devem ser adicionadas ressecção hepática em cunha do leito da vesícula e linfadenectomia.

\section{CÁLCULO ASSINTOMÁTICO}

Aproximadamente 80 a 90\% dos pacientes com litíase biliar são assintomáticos. Cálculo vesicular assintomático é definido como a presença de cálculo na vesícula biliar detectado incidentalmente em pacientes com ausência de 
história de cólica biliar ou uma das complicações da litíase biliar (colecistite aguda, pancreatite aguda, coledocolitíase), independentemente da presença ou ausência de sintomas inespecíficos como flatulência, intolerância a alimentos gordurosos e dispepsia.

O tratamento dos pacientes com cálculo vesicular assintomático permanece controverso. O processo decisório depende de vários fatores: história natural da litíase assintomática, custo e complicações da colecistectomia, idade do paciente, presença de doenças associadas, risco de carcinoma da vesícula biliar e o desejo do paciente.

A maioria dos estudos epidemiológicos evidenciou que cerca de $25 \%$ desenvolvem sintomas em um período de 10 anos, sendo que a primeira manifestação clínica é quase sempre cólica biliar. Apenas uma pequena porcentagem de pacientes apresenta uma complicação, como colangite e pancreatite biliar, sem ter tido pelo menos um episódio de cólica biliar.

Apesar do risco de colecistectomia eletiva em pacientes sem comorbidades ser muito baixo, a possibilidade de complicações graves, como lesão iatrogênica da via biliar e tromboembolismo, não é inexistente. Em decorrência do risco potencial da colecistectomia e do fato de a maioria dos pacientes com litíase biliar assintomática não apresentar manifestações clínicas, a maioria dos autores opta por conduta expectante. Colecistectomia é indicada seletivamente em alguns subgrupos de pacientes com litíase biliar assintomática, os quais serão discutidos a seguir. O paciente deve participar ativamente do processo decisório. Seu desejo e estilo de vida devem ser considerados.

\section{Laparotomia ou laparoscopia por outra indicação}

A colecistectomia deve ser realizada em pacientes com litíase vesicular assintomática submetidos à laparotomia ou laparoscopia por outra indicação, a menos que as condições gerais ou locais do paciente não permitam sua realização.

\section{Vesícula biliar calcificada}

A colecistectomia é indicada em decorrência da elevada incidência de carcinoma da vesícula, cerca de $22 \%$ dos casos.

\section{Candidatos a transplante de órgãos ou de medula óssea}

A colecistectomia está indicada neste grupo de pacientes porque a morbidade e a mortalidade são muito elevadas se estes desenvolvem sintomas após o transplante. 


\section{Anemia falciforme}

Pacientes com anemia falciforme e colelitíase assintomática devem ser submetidos à colecistectomia profilática pela dificuldade de diferenciar dor abdominal secundária a crise falciforme da cólica biliar ou colecistite aguda.

\section{Nutrição parenteral total}

A morbidade e a mortalidade dos pacientes com colelitíase que estão recebendo nutrição parenteral total é bastante elevada, 54 e 11\%, respectivamente, por causa da apresentação clínica atípica e das alterações fisiológicas associadas, tornando o diagnóstico de colecistite aguda tardio e difícil. Pacientes com litíase vesicular assintomática que necessitam de alimentação parenteral total devem ser submetidos à colecistectomia eletiva, se as condições médicas permitirem.

\section{Outros fatores}

O estilo de vida e o desejo do paciente devem ser considerados no processo decisório de indicação de colecistectomia de pacientes com colelitíase assintomática. A colecistectomia deve ser considerada em pacientes que viajam, principalmente para locais distantes de cuidado médico adequado, como viagens exóticas, de navio, entre outras.

\section{CONCLUSÕES}

- A quase totalidade dos pólipos da vesicular biliar é benigna e assintomática.

- Pólipo > $10 \mathrm{~mm}$, associado a cálculo ou que aumenta de tamanho deve ser submetido à colecistectomia.

- Todos os pólipos de vesícula biliar diagnosticados em pacientes com colangite esclerosante primária devem ser operados, independentemente do tamanho.

- A colecistectomia laparoscópica é o método preferencial para o tratamento de pólipos da vesícula biliar.

- Pólipos entre 6 e $10 \mathrm{~mm}$ devem ser seguidos com USG periódica por 5 a 10 anos.

- A maioria dos indivíduos com litíase vesicular permanece assintomática ao longo da vida.

- A conduta deve ser expectante na grande maioria dos indivíduos com litíase vesicular assintomática. Entretanto, alguns desses pacientes têm indicação 
de colecistectomia profilática: os submetidos à laparotomia ou laparoscopia por outra indicação apresentam vesícula calcificada, os submetidos a transplante de órgãos ou medula óssea, os que apresentam anemia falciforme ou os submetidos a nutrição parenteral prolongada.

- O estilo de vida e o desejo do paciente devem ser considerados no processo decisório de indicação de colecistectomia.

\section{REFERÊNCIAS BIBLIOGRÁFICAS}

1. Coelho JCU, Ramos Jr O. Litíase vesicular e colecistite crônica calculosa. In: Coelho JCU. Aparelho digestivo. Clínica e cirurgia. 4. ed. Rio de Janeiro: Atheneu; 2012. p.1833-48.

2. Elmasry M, Lindop D, Dunne DF, Malik H, Poston GJ, Fenwick SW. The risk of malignancy in ultrasound detected gallbladder polyps: a systematic review. Int J Surg. 2016;33PtA:28-35.

3. Sakorafas GH, Milingos D, Peros G. Asymptomatic cholelithiasis: is cholecystectomy really needed? A critical reappraisal 15 years after the introduction of laparoscopic cholecystectomy. Dig Dis Sci. 2007;52:1313-25.

4. Svassi-Rocha AL, Savassi-Rocha PR. Colesterolose, pólipos e adenomiomatose da vesícula biliar. In: Coelho JCU. Aparelho digestivo. Clínica e cirurgia. 4. ed. Rio de Janeiro: Atheneu; 2012. p.1825-32. 